\title{
An Empirical Study of the Relationship between Challenge Stressor, Hindrance Stressor and Job Burnout
}

\author{
Qingsong Zhu \\ Business School \\ Sichuan University \\ Chengdu, China 610065
}

\author{
Tingting Li \\ Business School \\ Sichuan University \\ Chengdu, China 610065
}

\begin{abstract}
Starting from the intrinsic attributes of stressors, this paper introduces achievement motivation as an intermediary and explores the influence of challenge and hindrance stress on job burnout. With a sample of 261 employees, a series of analysis were carried out by SPSS19.0 and AMOS21.0, and use the Bootstrap method to test the mediating effect. In summary, getting the following conclusions: Challenge stressors negatively predict job burnout, which hindrances Stressor positively predict job burnout; Achievement motivation plays a part intermediary role between challenge stress, hindrance stress and job burnout.
\end{abstract}

Keywords-challenge-hindrance stressor; achievement motivation; job burnout

\section{INTRODUCTION}

Job burnout was proposed by Freudenberge (1974) to express an individual's negative state in working situations, such as emotional exhaustion, physical exhaustion, and lack of job satisfaction. [1]Spector\&Jex (1998) has found that if a person is in a long-term stress, his psychology and behavior tend to be negative [2]. That's to say job stress is one of the important sources of job burnout [3][4].

Reviewing previous research, we can find that most studies only focus on the negative impact of stress on individuals. This may be because these studies are based on the "stimulus-response" model to examine the pressure.In recent years, some scholars started from the intrinsic properties of the source of stress and confirmed that the work stress can have both positive and negative consequences for the individual.

In view of this, Cavanaugh et al (2000) explicitly proposed the concept of "challenge-obstructive stress" and divided the pressure into two parts. According to the "good" and "bad" attributes of stress, the pressure sources were named as Challenging stress and Hindrance pressure. These two different sources of stress may have a completely different effect on individual work cognition, attitude and behavior. Therefore, it is necessary to re-examine the impact of different stressors on the level of burnout and improve the relationship between job stress and job burnout [5].
The job requirement-resource theory states that the impact of job stress on individual behavior is achieved by changing the individual's psychological resources. As an individual's positive psychological state, the achievement motivation is likely to be a challenge-impeding stress influencing the internal mechanism of job burnout. Based on this, this study introduces achievement motivation as an intermediary variable, in order to open the role of challengehindrance stress on job burnout, to enrich related theories and to provide reference for enterprise management practice.

\section{LITERATURE REVIEW}

\section{A. Challenge-hindrance Stressor}

Cavanaugh et al. clearly proposed the concept of a challenge-hindrance stressor and pointed out that if individuals think that they can overcome some kind of stress in their work, and that such pressure contributes to their own growth and professional development, then this pressure is challenging stress, such as work intensity, working hours, scope of duties, etc.; and if you think you can't overcome it, and this pressure will hinder your growth and development, then this pressure is hindrance stress, such as cumbersome processes, ambiguous working standards, etc. It has been widely recognized by the academic community [6].

\section{B. Achievement Motivation}

In the 1950s, McClelland et al formally proposed the concept of "achievement motivation" in the book "Achievement Motivation," which expressed that individuals would do their utmost to achieve a meaningful and valuable task for themselves.

\section{Job Burnout}

Job burnout refers to the negative state of energy exhaustion, negative slackness, or even the self-work meaning of an individual due to long-term high-intensity work environment. After the new century, the job burnout of enterprise employees is not to be ignored, so it is the trend of the field to study the job burnout of employees. 


\section{RESEARCH HYPOTHESIS}

\section{A. Challenges-hindrance Stress and Job Burnout}

In recent years, Cavanaugh and his team's focus on the two-dimensional structure of stressors has validated the different results of challenge- hindrance stress. Conclusions show that challenging stress can positively influence employee attitudes and behaviors, while hindrance stress is the opposite. When employees see perceived stress as a challenging stress, stress can be turned into motivation. Employees tend to actively associate stress with their career development, face up to difficulties, and firmly believe that they can solve them with a full working state and high sense of accomplishment, that is, challenging stress inhibits the generation of job burnout. When employees see perceived stress as a hindrance stress, the individual feels that they cannot afford or solve the current predicament. Pressure will become a resistance. Over time, employees will experience energy exhaustion, mental slackness, passiveness, and even suspicion of work state, in other words, hindrance stress can promote job burnout.

From existing studies, Beehr et al. (2000) pointed out that role conflict and role ambiguity pressures lead to individual adverse reactions and potentially harmful reactions [7]. Tai \& Liu (2007) pointed out that challenging stress is significantly negatively correlated with emotional exhaustion while hindrance stress is significantly positively correlated with it[8]. Jamal \& Ahmed (2010) proposed that challenging stress is significantly positively associated with physical symptoms and job burnout, and that hindrance stress is significantly negatively correlated with physical symptoms and job burnout[9]. Zhang Xiaoli et al. (2009) demonstrated that challenging stress can positively predict job satisfaction and negatively predict turnover intentions in the context of China, while hindrance pressure can positively predict turnover intentions and negatively predict job satisfaction [10].Based on the above analysis, the following hypotheses are proposed:

- H1: Challenge stressor can significantly negatively predict job burnout.

- H2: Hindrance stressor can significantly positively predict job burnout.

\section{B. Challenges-hindrance Stress and Achievement Motivation}

The demand for self-fulfillment of modern enterprise employees is very high. Whether or not they can achieve a sense of accomplishment and achieve professional success is a key factor in determining whether employees maintain their work enthusiasm or even decide to stay or leave. From the perspective of motivation, strong motivation for achievement should be the hard work of employees. One of the main reasons. High-intensity work pressure creates an environment for employees to work hard. Challenging pressures can inspire employees' work efficiency, strengthen their beliefs in hard work, and increase their drive for success (Webster et al., 2011). The sense of urgency to improve oneself, the fast-paced work provides employees with more practical opportunities and a broader space for self-value realization, which is more likely to bring a sense of accomplishment and improve the perception of job challenges (Boswell et al, 2004). Increase achievement motivation. The hindrance pressures that give employees an unreachable sense of difficulty will make them look at themselves negatively. Even if they complete the task, they will not have a sense of accomplishment. The sense of incompetence and helplessness of employees facing such pressure will reduce their achievements motivation. Based on the above analysis, the following hypotheses are proposed:

- H3: Challenging stress can significantly negatively predict achievement motivation.

- H4: Hindrance stress can significantly positively predict achievement motivation.

\section{The Mediating Role of Achievement Motivation}

Throughout the research in related fields, it can be found that the relationship between the challenge-hindrance stress and job burnout is not a simple linear correlation. There is a complex intermediary or adjustment mechanism between them. Most studies show that stress has an effect on employees' working conditions. The precondition for the impact is to change some of the employee's mental state (Beehr et al., 2000). In the era of knowledge economy, the needs and pursuits of employees have undergone significant changes. Achievement motivation has become an important source of power for stimulating employees' cognitions, attitudes, and behaviors. It is an important internal mechanism that promotes pressure as a driving force. Koestner \& Zuckerman (1990) pointed out that an individual with higher achievement motivation tends to show strong internal motivation and show more positive emotions[11]. In addition, scholars have also found that there is a positive correlation between achievement motivation and career choice, subjective well-being, emotional instability, life goals, and control points. Therefore, it can be concluded that achievement motivation is one of the important factors affecting job burnout. Therefore, the study believes that achievement motivation is most likely to be an important transmission mechanism that impedes stress on job burnout, and determines the ultimate influence of stress on burnout. So, we can suppose the following hypotheses.

- H5: Achievement motivation plays an intermediary role between challenging stressor and job burnout.

- H6: Achievement motivation plays an intermediary role between hindrance stressor and job burnout.

The theoretical model of this paper is shown in "Fig. 1". 


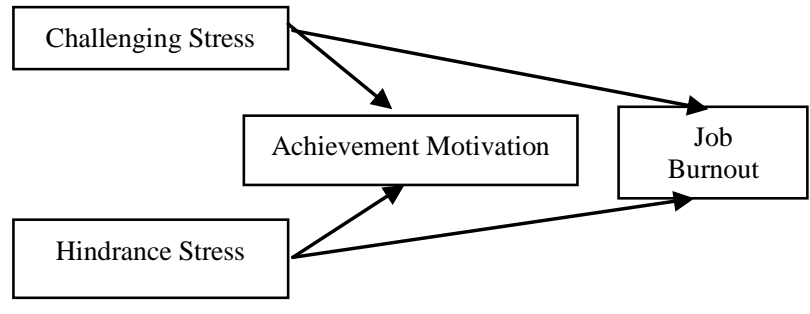

Fig. 1. Theoretical research model.

\section{RESEARCH DESIGN AND DATA ANALYSIS SAMPLE}

In this study, employees were selected as the survey objects. The questionnaires were distributed and collected mainly in the high-tech industrial development zones of Chengdu, Changzhi, and Jinan, and Zhongguancun Science Park in Beijing. The forms of questionnaire collection included on-site distribution and electronic questionnaires. A total of 340 questionnaires were distributed, excluding missing, multiple-choice and repeated-selection questionnaires. Among the remaining 261 questionnaires, the effective rate was $76.76 \%$. The basic conditions of the sample are shown in "Table I".

TABLE I. SCALE RELIABILITY ANALYSIS RESULTS

\begin{tabular}{llll}
\hline \multicolumn{1}{c}{ Variable Name } & \multicolumn{1}{c}{ Dimensions } & $\begin{array}{c}\text { Items } \\
\text { Crobach } \\
\text { Alpha }\end{array}$ \\
\hline Challenge- & Challenge stressor & 6 & 0.836 \\
Hindrance Stressor & Hindrance stressor & 5 & 0.743 \\
Achievement & Achievement Motivation & 30 & 0.887 \\
Motivation & job burnout & 15 & 0.840 \\
job burnout & ---- & 56 & 0.863 \\
Total scale & &
\end{tabular}

In the sample, women accounted for 56.7\%; In terms of age, $63.2 \%$ were younger than 26 , and $32.2 \%$ between 26 and 35 years old. In the background of education, the undergraduates accounted for $65.1 \%$, with $20.3 \%$ of the subjects with master's degree or above. As for marital status, married account for $80.5 \%$; In terms of working years, $69 \%$ of the participants were less than three years, and $19.2 \%$ had more than three years' working experience. At the level of position, $68.2 \%$ are ordinary employees, $23.4 \%$ are grassroots managers, $7.7 \%$ are middle managers and $0.8 \%$ is senior managers.

\section{A. Measurement Scale}

Challenge-hindrance stress was developed by Cavanaugh et al. in the study of 11 items including challenging stress (6 items) and hindrance stress (5 items). The achievement motivation adopts the AMS scale compiled by Gjesme\& Nygard; Job burnout is based on the MBI-GS scale developed by Maslach et al. All the scales are the mature scale which is widely recognized by the academic circle and highly used. The reliability of the scale can be obtained by the initial guarantee. This research report is a self-report questionnaire, adopts the likert 5 point scoring method, " $1 "=$ "strongly disagree", "2" = "not agree", "3" = "not sure", "4" = "agree", "5" = "strongly agree".

\section{B. Data Analysis}

1) Scale reliability and validity analysis: SPSS 19.0 was used to analyze the reliability of the total and subscales respectively, and the internal consistency coefficient ( $\alpha$ value) was selected as the index. From "Table II", it can be seen that the $\alpha$ values of all scales are all above 0.7 , indicating that The reliability of the scale is good and subsequent data analysis can be performed.

TABLE II. SCALE VALIDITY ANALYSIS RESULTS

\begin{tabular}{lllllllrr}
\hline \multicolumn{1}{c}{ Variable Name } & KMO & P-value & $\mathbf{X}^{2} / \mathbf{d f}$ & RMSEA & GFI & NFI & IFI & CFI \\
\hline Challenge-Hindrance & 0.816 & .000 & 2.640 & .079 & .924 & .891 & .929 & .928 \\
Stressor & & & & & & & \\
Achievement Motivation & 0.895 & .000 & 2.729 & .082 & .903 & .939 & .927 & .932 \\
job burnout & 0.875 & .000 & 1.942 & .060 & .924 & .908 & .953 & .953 \\
\hline
\end{tabular}

The maturity scale can basically guarantee the content factor analysis. The use of AMO21.0 to fit the scale, the validity of the scale, so this study focuses on the test of the structure validity. First, exploratory factor analysis was carried out by SPSS19.0. The results showed that the KMO values of each subscale were all greater than 0.7 , and $\mathrm{P}$ values were all less than.05, so it is suitable for confirmatory results are shown in "Table III", the scale of X2/df is less than 3; and RMSEA was less than 0.1; the absolute fit index of GFI was greater than 0.9 ; the relative fit index NFI, IFI and CFI were the size of 0.9 , indicating the scale of good fitting, structure validity of good performance.

TABLE III. T-TeST AND ANOVA ANALYSIS RESUlts

\begin{tabular}{|c|c|c|c|c|c|c|}
\hline \multirow{2}{*}{ Control variables } & \multicolumn{2}{|r|}{ T-Test } & \multicolumn{4}{|c|}{ One-Way ANOVA } \\
\hline & Gender & Marital Status & Sge & Education & Working years & Position level \\
\hline \multirow{3}{*}{ Challenge stressor } & F/Sig. & F/Sig. & F/Sig. & F/Sig. & F/Sig. & F/Sig. \\
\hline & $.037 /$ & $1.17 /$ & .106 & 1.783 & 1.013 & 1.314 \\
\hline & .848 & .280 & 1.956 & $/ .151$ & 1.387 & 1.270 \\
\hline \multirow{2}{*}{ Hindrance stressor } & .062 & .297 & .244 & 2.424 & 1.454 & 1.625 \\
\hline & 1.804 & 1.586 & 1.865 & 1.066 & 1.228 & /.184 \\
\hline \multirow{2}{*}{ Achievement Motivation } & .001 & .192 & .509 & 2.889 & 1.540 & .466 \\
\hline & 1.970 & 1.662 & 1.677 & 1.036 & 1.205 & 1.706 \\
\hline \multirow{2}{*}{ job burnout } & 1.902 & 8.55 & 1.12 & 4.244 & 1.530 & 619 \\
\hline & $/ .169$ & 1.004 & 1.342 & /.006 & /.207 & 1.603 \\
\hline
\end{tabular}


2) Harman single factor test: The common method deviation refers to the artificial covariation of the relationship between variables caused by the same data source or rater, the same measurement environment, and project context. The questionnaire for this study is selfreported, so it is necessary to perform homology bias analysis. According to Zhou\&Long (2004), the Harman single factor test was conducted to test the results of unrotated exploratory factor analysis[12]. The largest factor that could be precipitated could explain the variation of $20.729 \%$, which is far less than the upper limit of $50 \%$. Therefore, this study can be considered as the common method deviation problem is not serious and will not affect the results of the study.

3) T-Test and One Way ANOVA: The level of control variables may also influence the conclusions of the study. Therefore, T-Test and One-Way ANOVA were used to test whether different levels of control variables had significant differences in different research variables. In this study, TTest was used to test gender and marital status. One-Way ANOVA was used to test whether the differences in age, education background, working years, and job level were significant differences in the study variables. The results are shown in "Table IV":

TABLE IV. CORRELATION ANALYSIS RESULTS

\begin{tabular}{|c|c|c|c|c|c|c|}
\hline \multirow{2}{*}{$\begin{array}{c}\text { Control } \\
\text { Variables }\end{array}$} & \multirow{2}{*}{ M } & \multirow{2}{*}{ SD } & \multicolumn{4}{|c|}{ Correlation } \\
\hline & & & 1 & 2 & 3 & 4 \\
\hline $\begin{array}{l}\text { 1.Challenge } \\
\text { stressor }\end{array}$ & 3.441 & .727 & 1 & & & \\
\hline $\begin{array}{l}\text { 2.Hindrance } \\
\text { stressor }\end{array}$ & 2.876 & .867 & $-187 * *$ & 1 & & \\
\hline $\begin{array}{l}\text { 3.Achievement } \\
\text { Motivation }\end{array}$ & .292 & .997 & $.448^{* * *}$ & - & 1 & \\
\hline 4.job burnout & 2.641 & .629 & $.506^{* *}$ & $.493^{* *}$ & $-494 * *$ & 1 \\
\hline
\end{tabular}

As can be seen from the above table, there is no significant difference in gender, age, years of service, and job level among all the study variables (Sig>.05).Marital status and educational background are different in achievement motivation and job burnout, so in subsequent tests need to control these two variables.

4) Correlation analysis: A bivariate correlation analysis was performed on all study variables. The results are shown in Table 5. It can be seen that challenge stressor is significantly positively correlated with achievement motivation ( $\mathrm{r}=.448 ; \mathrm{P}<.01)$, and significantly negatively correlated with job burnout $(\mathrm{r}=-.506 ; \mathrm{P}<.01)$; Hindrance stressor and achievement motivation. $(\mathrm{r}=-.337$; $\mathrm{P}<.01)$ was significantly negatively correlated with job burnout ( $\mathrm{r}=.493$; $\mathrm{P}<.01)$; Achievement motivation was significantly negatively correlated with job burnout $(\mathrm{r}=.494$; $\mathrm{P}<.01)$; Thus it is assumed that $\mathrm{H} 1, \mathrm{H} 2, \mathrm{H} 3$, and $\mathrm{H} 4$ have been initially supported.

5) Regression Analysis: In this study, a hierarchical regression analysis of the relevant variables was performed using SPSS19.0. The first step was to add the control variables with significant differences at each level on the corresponding study variables. The second step was to add the independent variables, and observe how coefficient $\beta, \Delta \mathrm{F}$ values, $\mathrm{R}^{2}$ and significant level change, the results are shown in Table 6. It can be seen that after controlling marital status and education background, challenge stressor $\left(\Delta \mathrm{F}=74.2, \quad \Delta \mathrm{R}^{2}=.166, \quad \mathrm{P}<.001\right)$ and hindrance stressor $\left(\Delta \mathrm{F}=64.1, \Delta \mathrm{R}^{2}=.145, \mathrm{P}<.001\right)$ has a significant regression equation for job burnout, and challenge stressor has a negative effect on job burnout $(\beta=-.42, P<.001)$, while hindrance stressor has a positive effect on job burnout $(\beta$ $=.336, \mathrm{P}<.001)$, which shows that hypothesis $\mathrm{H} 1$ and hypothesis $\mathrm{H} 2$ are true; After controlling the educational background, challenge stressor $\left(\Delta \mathrm{F}=54.9, \Delta \mathrm{R}^{2}=.163\right.$, $\mathrm{P}<.001)$ and hindrance stressor $\left(\Delta \mathrm{F}=23.4, \Delta \mathrm{R}^{2}=.08, \mathrm{P}<.001\right)$ The regression equations for achievement motivation are all significant. The challenge stressor $(\beta=.598, \mathrm{P}<.001)$ has a positive influence on achievement motivation and hindrance stressor. $\quad(\beta=-.37, \quad \mathrm{P}<.001)$ has a negative effect on achievement motivation, indicating that hypothesis $\mathrm{H} 3$ and hypothesis $\mathrm{H} 4$ are true.

TABLE V. HIERARCHICAL REGRESSION ANALYSIS RESULTS

\begin{tabular}{|c|c|c|c|c|c|c|c|c|}
\hline \multirow{2}{*}{\multicolumn{2}{|c|}{ Hypothesis }} & \multirow{2}{*}{ variables } & \multicolumn{2}{|c|}{ Step1 } & \multicolumn{4}{|c|}{ Step2 } \\
\hline & & & $\beta$ & $t$ & $\beta$ & $t$ & $\Delta F$ & $\Delta R^{2}$ \\
\hline CS -JB & H1 & $\begin{array}{l}\text { MS } \\
\text { EB } \\
\text { CS }\end{array}$ & $\begin{array}{l}-.250^{\circ} \\
-.186^{* *}\end{array}$ & $\begin{array}{l}-2.61^{*} \\
-3.37^{* *}\end{array}$ & $\begin{array}{l}-.198^{*} \\
-.135^{* *} \\
-.42^{* * *}\end{array}$ & $\begin{array}{l}-.125^{*} \\
-.148^{* * *} \\
-.48^{* * *}\end{array}$ & $74.2^{* * * *}$ & $.166^{* * *}$ \\
\hline $\begin{array}{l}\text { HS- } \\
\text { JB }\end{array}$ & $\mathrm{H} 2$ & $\begin{array}{l}\text { MS } \\
\text { EB } \\
\text { HS }\end{array}$ & $\begin{array}{l}-.250^{\circ} \\
-.186^{* *}\end{array}$ & $\begin{array}{l}-2.61^{*} \\
-3.37^{* *}\end{array}$ & $\begin{array}{l}-.148 \\
-.127^{*} \\
.336^{* * *}\end{array}$ & $\begin{array}{l}-1.724 \\
-2.59^{*} \\
8.52^{* * *}\end{array}$ & $64.1^{m+m}$ & $.145^{\text {mat }}$ \\
\hline CS-AM & $\mathrm{H} 3$ & $\begin{array}{l}\text { EB } \\
\text { CS }\end{array}$ & $.229^{\prime \prime}$ & $2.590^{*}$ & $\begin{array}{l}.159^{*} \\
.598^{*+*}\end{array}$ & $\begin{array}{l}1.984^{2} \\
7.85^{*+4}\end{array}$ & $54.9^{2 m+n}$ & $.163^{2+2 n t}$ \\
\hline HS-AM & $\mathrm{H} 4$ & $\begin{array}{l}\text { EB } \\
\text { HS }\end{array}$ & $.229^{*}$ & $2.59^{3}$ & $\begin{array}{l}.169^{*} \\
-.37^{\prime \cdots}\end{array}$ & $\begin{array}{l}2.00^{*} \\
-5.5^{* * 3}\end{array}$ & $23.4^{* * *}$ & $.08^{* * 3}$ \\
\hline
\end{tabular}

${ }^{b}$ PS : ${ }^{*}$ p $<.05 ; * *$ p $<.01 ; * * *$ p $<.001$; CS represent Challenge Stressor ; HS represent Hindrance Stressor;AM represent Achievement Motivation;JB represent Job Burnout.MS represent Marital Status; EB represent

6) Mediating Effect Test: This article uses the Bootstrap method proposed by Preacher \& Hayes (2004) to test the mediation[13]. The test results are shown in Table 7. It can be seen that the mediating effect of achievement motivation on challenge stressor and occupational burnout is significant, and the interval (LLCI=-.1933, ULCI=- .0696) does not 
contain 0 , and the mediating effect size is -.1295 . That is, assuming that $\mathrm{H} 5$ is true, and $\mathrm{C}^{\prime}$ is also significant, the interval $(-.4044,-.2123)$ does not contain 0 , and thus is a partial intermediary. The mediating effect between hindrance stressor and burnout is significant. The interval $(\mathrm{LLCI}=.0489$, ULCI $=.1422)$ does not contain 0 , and the mediating effect is .0904. That is, H6 is assumed to be true, and $C^{\prime}$ is also significant, and the interval $(.1921, .3427)$ does not contain 0 , and thus is also part of the intermediary, that is to say, the achievement motivation plays a partial intermediary role between challenge stress and job burnout, hindrance stressor and job burnout[14].

TABLE VI. MEDIATION ANALysis Results

\begin{tabular}{lllll}
\hline X:Challenge & \multicolumn{5}{c}{ Direct effect of X on Y } \\
Stressor & Effect & SE & LLCI & ULCI \\
Y:Job Burnout & -.3083 & .0488 & -.4044 & -.2123 \\
M:Achievement & \multicolumn{4}{c}{ Indirect effect of X on Y } \\
Motivation & Effect & BootSE & BootLLCI & BootULCI \\
& -.1295 & .0316 & -.1933 & -.0696 \\
\hline \multirow{4}{*}{ X:Hindrance } & \multicolumn{5}{c}{ Direct effect of X on Y } \\
Stressor & Effect & SE & LLCI & ULCI \\
Y:Job Burnout & .2674 & .0383 & .1921 & .3427 \\
M:Achievement & Effect & Indirect effect of X on Y \\
Motivation & .0904 & .0240 & BootLLCI & BootULCI \\
& & \multicolumn{5}{c}{.0489} & .1422 \\
\hline
\end{tabular}

\section{CONCLUSION}

The challenge stressor has a significant negative predictive power to job burnout, and the hindrance stressor has a significant positive predictive power to job burnout. The challenge stress is mainly due to the intensity of work, working time and duty scope. Staff believes they can overcome these pressures, and view the stress as the driving force, is very conducive to the growth and development of employee occupation career. And this perssure can have a positive impact on the employee's emotion, attitude and behavior, so as to reduce the occupation burnout. The hindrance stressoris mainly due to the work pressure standard is fuzzy, role conflict and job insecurity and other factors, the staff suggested that he cannot overcome and these will hinder the occupation career development pressure subjectively, it will reduce the working enthusiasm, lead to exhaustion, weak thought and other negative phenomena, job burnout.

Achievement motivation plays a part of mediating role in both challenge stressor and job burnout, hindrance stressor and job burnout. The conclusion of the study shows that work stress can affect the job burnout, a large part of the reason is whether change staff's achievement motivation. Challenge stressor can improve the level of achievement motivation to avoid the possibility of the employees' negative attitude or behavior, thereby inhibiting occupation burnout. However, hindrance pressure is a negative effect on employees' self and work evaluation, emotional exhaustion and energy degradation, which leads to job burnout.

The samples belong to cross sectional data, and there are some homologous deviations. Though Harman analysis, we can see that the homologous problem is not serious in this study, but it is still a deficiency of research. The future research can divide the time to collect the sample, and use the paired data to retest the model. Besides, achievement motivation plays a partial mediating role in work stress, while in the text $\left(\mathrm{a}^{*} \mathrm{~b}^{*} \mathrm{C}^{\prime}\right)$ is positive, so there are other missing complementary intermediaries between the two[15], which can be based on more intermediary variables in future research.

\section{REFERENCES}

[1] H Freudenberger, "Staff Burnout," Journal of soeial Issues, 1974, pp.159-165.

[2] PE Spector and SM Jex, "Development of Four Self-Report Measures of Job Stressors and Strain: Interpersonal Conflict at Work Scale, Organizational Constraints Scale, Quantitative Workload Inventory, and Physical Symptoms Inventory," Journal of Occupational Health Psychology, 1998, pp. 356-67.

[3] C Maslach and SE Jackson, "The measure of experienced burnout," Journal of Organizational Behavior, 1981, pp.99-113.

[4] Tian Bao, Li xupei, Teng xiujie and Shi kan,"The Relationship between Stress Situation Cognition and Job Burnout," Psychological Science, 2012, pp.165-170.(In Chinese)

[5] MA Cavanaugh, WR Boswell, MV Roehling et al,“An empirical examination of self-reported work stress among U.S. managers," The Journal of Applied Psychology, 2000,pp. 65-74.

[6] JR Webster, TA Beehr and K Love,"Extending the challengehindrance model of occupational stress: The role of appraisal," Journal of Vocational Behavior,2011, pp.505-516.

[7] TA Beehr, SM Jex and BA Stacy et al,"Workstressors and coworker support as predictors of individual strain and job performance," Journal of Organizational Behavior, 2000,pp. 391-405.

[8] WT Tai and SC Liu, “An Investigation of The Influences of Job Autonomy and Neuroticism on Job Stressor-strain Relations," Social Behavior \&Personality: An International Joum, 2007, pp.1007-1019.

[9] M Jamal and SW Ahmed, "Job Stress, Stress-Prone Type A Behavior, and Personal and Organizational Consequences," Canadian Journal of Administrative Sciences,2010,pp.360-374.

[10] Zhang wenli and Lu changqin, "The relationship between the challenge - hindrance stressor and the employee's psychology and behavior: the moderating effect of self efficacy," Journal of Psychology, 2009, pp.501-509. (In Chinese)

[11] R Koestner,M Zuckerman amd J Olsson,"Attributional style, comparison focus of praise, and intrinsic motivation," Journal of Research in Personality, 1990,pp. 87-100.

[12] Zhou hao and Long lirong,"Statistical test and control method of common method deviation," Advances in psychological science, 2004, pp.942-950. (In Chinese)

[13] KJ Preacher and AF Hayes, "SPSS and SAS procedures for estimating indirect effects in simple mediation models," Behavior Research Methods, Instruments, \& Computers,2004,pp.717-731.

[14] X Zhao, JG Lynch and Q Chen,"Reconsidering Baron and Kenny: myths and truths about mediation analysis,"Journal of Consumer Research,2010,pp.197-206.

[15] Chen rui, Zheng yuhuang and Liu wenjing,"Mediation Analysis: Principles, Procedures, Bootstrap Methods, and Applications," Journal of Marketing Science,2013,pp.120-135. (In Chinese) 